\title{
Phylogenomic analysis of Candidatus 'Izimaplasma' species: free-living representatives from a Tenericutes clade found in methane seeps
}

\author{
Connor T Skennerton ${ }^{1}$, Mohamed F Haroon ${ }^{2,6}$, Ariane Briegel ${ }^{3,7}$, Jian Shi ${ }^{3}$, Grant J Jensen ${ }^{3,4}$, \\ Gene W Tyson ${ }^{2,5}$ and Victoria J Orphan ${ }^{1}$ \\ ${ }^{1}$ Division of Geological and Planetary Sciences, California Institute of Technology, Pasadena, CA, USA; \\ ${ }^{2}$ Australian Center for Ecogenomics, School of Chemistry and Molecular Biosciences, University of \\ Queensland, St Lucia, Queensland, Australia; ${ }^{3}$ Division of Biology and Biological Engineering, California \\ Institute of Technology, Pasadena, CA, USA; ${ }^{4}$ Howard Hughes Medical Institute, California Institute of \\ Technology, Pasadena, CA, USA and ${ }^{5}$ The Advanced Water Management Center, University of Queensland, \\ St Lucia, Queensland, Australia
}

\begin{abstract}
Tenericutes are a unique class of bacteria that lack a cell wall and are typically parasites or commensals of eukaryotic hosts. Environmental 16S rDNA surveys have identified a number of tenericute clades in diverse environments, introducing the possibility that these Tenericutes may represent non-host-associated, free-living microorganisms. Metagenomic sequencing of deep-sea methane seep sediments resulted in the assembly of two genomes from a Tenericutes-affiliated clade currently known as 'NB1-n' (SILVA taxonomy) or 'RF3' (Greengenes taxonomy). Metabolic reconstruction revealed that, like cultured members of the Mollicutes, these 'NB1-n' representatives lack a tricarboxylic acid cycle and instead use anaerobic fermentation of simple sugars for substrate level phosphorylation. Notably, the genomes also contained a number of unique metabolic features including hydrogenases and a simplified electron transport chain containing an RNF complex, cytochrome $b d$ oxidase and complex $\mathrm{I}$. On the basis of the metabolic potential predicted from the annotated genomes, we devised an anaerobic enrichment media that stimulated the growth of these Tenericutes at $10^{\circ} \mathrm{C}$, resulting in a mixed culture where these organisms represented $\sim 60 \%$ of the total cells by targeted fluorescence in situ hybridization (FISH). Visual identification by FISH confirmed these organisms were not directly associated with Eukaryotes and electron cryomicroscopy of cells in the enrichment culture confirmed an ultrastructure consistent with the defining phenotypic property of Tenericutes, with a single membrane and no cell wall. On the basis of their unique gene content, phylogenetic placement and ultrastructure, we propose these organisms represent a novel class within the Tenericutes, and suggest the names Candidatus 'Izimaplasma sp. HR1' and Candidatus 'Izimaplasma sp. HR2' for the two genome representatives.
\end{abstract}

The ISME Journal (2016) 10, 2679-2692; doi:10.1038/ismej.2016.55; published online 8 April 2016

\section{Introduction}

Mollicutes are bacteria that lack a cell wall and typically form close associations with animal and plant hosts as commensals or parasites (Razin et al., 1998). Taxonomically, the Mollicutes are

Correspondence: CT Skennerton or VJ Orphan, Division of Geological and Planetary Sciences, California Institute of Technology, 1200 East California Blvd, MC 100-23, Pasadena, CA 91125, USA.

E-mail: c.skennerton@gmail.com or vorphan@gps.caltech.edu ${ }^{6}$ Present address: Red Sea Research Center, King Abdullah University of Science and Technology (KAUST), Thuwal 239556900, Saudi Arabia.

${ }^{7}$ Present address: Sylvius Laboratorium, Leiden University, Sylviusweg 72, 23333 BE Leiden, The Netherlands.

Received 13 January 2016; revised 29 February 2016; accepted 4 March 2016; published online 8 April 2016 currently classified as the only class within the phylum Tenericutes, however the phylogeny of ribosomal rRNA genes and proteins places the Mollicutes as members of the Firmicutes and close relatives of the firmicute class Erysipelotrichia (Ogawa et al., 2011; Davis et al., 2013; Yutin and Galperin, 2013). Most cultured Mollicutes can be divided into four main clades based on 16S rDNA sequences: the hominis group, which contains some members of the genus Mycoplasma; the pneumoniae group, which includes some Mycoplasma and the Ureaplasma; the spiroplasma group, which includes the genera Spiroplasma, Entomoplasma and Mesoplasma; and the anaeroplasma group, which includes the genera Anaeroplasma, Acholeplasma and Candidatus Phytoplasma (Davis et al., 2013). There are also a number of peripheral clades that 
contain cultured organisms such as Haloplasma contractile (H. contractile), Turicibacter sanguinis (T. sanguinis) and clades known only through environmental community profiling of $16 \mathrm{~S}$ rDNA, such as 'RF9' and 'NB1-n' (naming based on the SILVA 119 database).

The most widely studied Mollicutes, the Mycoplasma, are important as medical and agricultural parasites that have adapted to host-associated environments where nutrients are readily available. Parasitic Mollicutes have undergone significant genome reduction that has resulted in the loss of most biosynthetic pathways for nucleotides, amino acids and fatty acids, as well as functions likely present in their firmicute ancestors such as sporulation and cell wall production (Razin et al., 1998). The very smallest Mollicutes species contain $\sim 500 \mathrm{kbp}$ genomes that have been of great interest for synthetic biology (Gibson et al., 2010) and as model organisms for determining the minimal genetic content required for life (Glass et al., 2006). However, analysis of other mollicute clades has revealed a broader range of genome sizes; the Acholeplasma have an average genome length of $\sim 1.2 \mathrm{Mbp}$, while closely related organisms, $T$. sanguinis and $H$. contractile have 2.9 and $3.2 \mathrm{Mbp}$ genomes, respectively (Antunes et al., 2011; Cuív et al., 2011; Lazarev et al., 2011; Kube et al., 2013).

The metabolisms of all previously studied Mollicutes exclusively rely on substrate-level phosphorylation for ATP generation. Mollicute genomes sequenced to date lack a complete tricarboxylic acid cycle and cytochromes or quinones for use in oxidative phosphorylation (Razin, 2006). Respiration is achieved through the fermentation of carbohydrates, small organic acids or through the arginine dihydrolase pathway (Razin, 2006). In the Ureaplasma, an alternative pathway exists that couples urea hydrolysis with the generation of a membrane potential to generate ATP (Smith et al., 1993).

Recently, $H$. contractile, a wall-less bacteria phylogenetically affiliated with the Mollicutes was cultured from the brine-sediment interface of the Red Sea (Antunes et al., 2008). Genome sequencing and phylogenetic analysis of $H$. contractile revealed some features common to Mollicutes such as a lack of a cell wall, however its large genome size and lack of known host organism were inconsistent with classification as a member of the Mollicutes (Antunes et al., 2008, 2011). Haloplasma appears to be a basal lineage of the Mollicutes and is most closely related to $T$. sanguinis (a gram positive firmicute) and several other environmental clades. One of these clades, 'NB1-n' contains 100 sequences from 16S rDNA environmental surveys from diverse habitats such as marine and freshwater sediments, hypersaline microbial mats, rumen and anaerobic digester sludge. Here we present genome sequences of two representatives of clade 'NB1-n', reconstructed from metagenomic sequencing of marine methane seep sediment communities. These two genomes are more metabolically diverse than known Mollicutes and do not appear to be hostassociated. However, they branch with members of the Acholeplasmatales when using conserved ribosomal and non-ribosomal genes and lack a cell wall, the distinctive phenotypic feature of Tenericutes.

\section{Materials and methods}

Sample collection and incubation

Methane seep sediment samples, labeled 3730, 51335 and 5579, were collected from Hydrate Ridge, off the coast of Oregon on two separate cruises, AT 15-68 in August 2010 for 3730 and AT 18-10 in September 2011 for 5579 and 5133-5. Seep sediment was collected using the HOV Alvin (2010) or ROV Jason II (2011) with a push core and immediately processed shipboard as described previously (Orphan et al., 2001). Sample 3730 was collected on dive AD4635 within a Calyptogena clam bed from Hydrate Ridge south ( $44^{\circ} 43.09 \mathrm{~N} ; 125^{\circ} 9.14 \mathrm{~W}$; depth $776 \mathrm{~m}$ ), and 5133-5 and 5579 were collected from a white microbial mat at Hydrate Ridge north, station 7

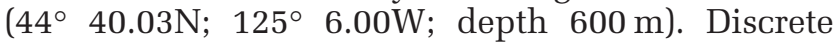
sediment horizons from each of the cores were transferred to glass pyrex bottles $(1 \mathrm{~L})$, sparged with methane and stoppered with a butyl rubber stopper. Sediments were maintained at $4^{\circ} \mathrm{C}$ in the dark until processing in the lab for large-scale microcosm experiments. For sample 3730, sediment from 0 to $6 \mathrm{~cm}$ depth was combined and used in a 30-month microcosm incubation experiment with a methane headspace before DNA extraction and metagenome sequencing. For sample 5133-5, the 0-9-cm sediment horizon was collected and incubated for 15 months before DNA extraction. For sample 5579, 0-12 cm sediment was collected and incubated for 15 months. Sediment microcosm incubations from all samples were mixed 1:3 with anoxic $0.2 \mu \mathrm{m}$ filtered bottom water to make a slurry and maintained anaerobically, with a 2 -atm overpressure of methane at $4^{\circ} \mathrm{C}$. DNA was extracted from the sediment slurry using the $\mathrm{MO}$ BIO Powersoil DNA extraction kit (cat \# 12888; MO BIO Laboratories Inc., Carlsbad, CA, USA). Extracted DNA was further purified using a CsCl gradient before metagenome library preparation (Saunders and Burke, 1990).

Sequencing and assembly of Izimaplasma genomes Extracted DNA from samples 3730, 5133-5 and 5579 were sequenced using Illumina HiSeq2000 platform (Illumina, Inc., San Diego, CA, USA) at the University of Queensland, Australia. Samples 3730 and 5133-5 were further sequenced a second time at Argonne National Laboratory to increase sequencing depth. Raw sequencing reads were quality trimmed (using a threshold of 0.05) and assembled using CLCBio genomics workbench 6.0 (www.clcbio.com). 
Sequencing reads from each metagenome were assembled individually and two assemblies were performed by combining sequencing reads from the three data sets sequenced at the University of Queensland and all five data sets sequenced at both Argonne and the University of Queensland. For each assembly, the raw sequencing reads from all data sets were aligned to contigs $>500 \mathrm{bp}$ with BWA 0.7.5a (Li, 2013) using the 'mem' algorithm and converted into bam files using samtools 0.1.19 (Li et al., 2009). These bam files were used as input for GroopM 0.2 (Imelfort et al., 2014), which generated genome bins. The 'refine' command in GroopM was used to improve the genome bins manually by removing contigs with unusual coverage or tetramer frequencies. The completeness and contamination of genome bins was determined using CheckM 0.6.0 (Parks et al., 2014).

The Izimaplasma sp. HR1 genome was further improved with additional genome finishing and reassembly. The draft Izimaplasma sp. HR1 genome contained four pieces, including a single doublecopy transposon. Analysis of paired-end read mapping from Izimaplasma sp. HR1 suggested an order of the contigs. The orientation a single contig bordered by the transposon was confirmed by designing PCR primers on either side of the transposon for both of the possible orientations.

\section{Genome annotation and pathway analysis}

The two Izimaplasma genomes were annotated using Prokka 1.10 (Seemann, 2014) and the KAAS web annotation server (Moriya et al., 2007). Prokka used as components: Prodigal 2.5 (Hyatt et al., 2010), Aragorn 1.2.34 (Laslett and Canback, 2004), SignalP 4.0 (Petersen et al., 2011), hmmer 3.0 (http://hmmer. org) and blast+ 2.2.26 (Camacho et al., 2009). As a supplement to this annotation, the KAAS web server was used to determine KEGG orthologies and map genes onto KEGG pathways. The genetic code of both genomes was determined using FACIL (Dutilh et al., 2011). Orthologs were detected between Izimaplasma and other mollicute genomes sourced from Integrated Microbial Genomes (IMG) and NCBI genomes databases using proteinortho 5.0 (Lechner et al., 2011). Metabolic pathways from previously sequenced mollicute genomes were compared using the PATRIC web server (Wattam et al., 2014).

\section{$16 S$ rRNA gene tree construction}

The two Izimaplasma 16S rRNA gene sequences were imported into ARB 6.0.2 (Ludwig et al., 2004) and aligned in ARB using a PT server generated from the SILVA 119 release database. A maximum likelihood tree of all sequences in SILVA 119 that were part of the 'NB1-n' clade was generated with RAxML 8.1.7 (Stamatakis, 2014) with 100 replicates of the rapid bootstrap analysis and GTR+GAMMA model of substitution rates (commandline: raxmlHPCPTHREADS-AVX -f a -k -x 12345 -p 12345 -N 100 -m
GTRGAMMAI). In addition, a second tree was constructed with RAxML independent of the SILVA alignment. Sequences from the Tenericutes, Erysipelotrichia, and representative Firmicutes and Actinobacteria were aligned with Infernal v1.1.1 (Nawrocki and Eddy, 2013) using the bacterial covariance model provided by the Ribosomal Database Project (RDP; https://rdp.cme.msu.edu/misc/resources.jsp\#a ligns). A phylogenetic tree was constructed using RAxML with the following parameters: raxmlHPCPTHREADS-SSE3 -f a -k -x 67842 -p 19881103 -N 100 -T 16 -m GTRGAMMAI.

\section{Genome tree construction}

The genome tree was constructed from a concatenated alignment of 38 protein-coding genes that are universally distributed and in a single copy in both archaea and bacteria (Wu et al., 2013). The basis for the tree included both draft and finished genomes from the NCBI and IMG databases that were part of the Tenericutes and phylogenetically related members of the Firmicutes. The marker genes were identified in each genome using hmmer 3.0 with the 'hmmalign' command (http://hmmer.org). A maximum likelihood tree was created using FastTree 2.1.7 (Price et al., 2010) with the default settings.

\section{RpoB and EF-tu tree construction}

RpoB or EF-tu sequences were identified in genomes downloaded from IMG genomes using the hidden markov models (HMMs) TIGR02013, TIGR03670 and TIGR00485 from TIGRfams (http://www.jcvi.org/cgibin/tigrfams/index.cgi). EF-tu sequences were aligned using hmmalign (http://hmmer.org), with the TIGRfam model (TIGR00485). RpoB sequences were aligned using muscle 3.8.31 (Edgar, 2004). Phylogenetic trees were constructed using FastTree 2.1.7 (Price et al., 2010).

\section{Cytochrome bd oxidase tree construction}

Sequences belonging to PF01654 were downloaded from Pfam (http://pfam.xfam.org/family/PF01654/ alignment/long/gzipped) and were clustered using cd-hit 4.6.1 (Li and Godzik, 2006) at 90\% identity to generate a representative set of sequences from previously published genomes. The same HMM was used to search against open reading frames translated from the contigs of the metagenomes using hmmsearch 3.1. Significant $(<1 \mathrm{e}-100)$ complete protein sequences were added to the representative set of published sequences, aligned using muscle 3.8.31 and a phylogenetic tree was constructed using FastTree 2.1.7.

Fluorescence in situ hybridization

A FISH oligonucleotide probe, Izzy659 (5'-ATTCCA CTAACCTCTGCC-3'), was designed to target some 
members of the 'NB1-n' clade that contained the two genome representatives. Using the SILVA 119 database and the probe design tool in ARB 6.0.2 (Ludwig et al., 2004) we designed a probe that targeted $1516 \mathrm{~S}$ rRNA sequences, including the two genome representatives (Supplementary Figure S2). FISH hybridization was performed on sediment \#5579-an anaerobic incubation maintained with a 2-atm methane headspace at $4^{\circ} \mathrm{C}$. \#5579 samples were fixed with $3 \%$ formaldehyde for $1.5 \mathrm{~h}$ at $4^{\circ} \mathrm{C}$, washed with $1 \times$ phosphate-buffered saline, and stored in 1:1 $1 \times$ phosphate-buffered saline:ethanol. The optimal formamide concentration for the Izzy659 probe was determined empirically through FISH hybridizations at $20 \%, 30 \%$ and $40 \%$. Formamide concentrations of $30 \%$ gave the brightest fluorescence signal. FISH hybridizations were performed on glass slides at $46^{\circ} \mathrm{C}$ for $2 \mathrm{~h}$ using the protocol described in Pernthaler et al. (2001) with $5 \mathrm{ng} \mathrm{ml}^{-1}$ of Eub338-FITC and Izzy659-Cy3 and a formamide stringency of $30 \%$. Slides were dried in the dark and then counterstained with $5 \mathrm{mg} \mathrm{ml}^{-1}$ of 4',6'-diamidino-2-phenylindole (DAPI) in CITIFLUOR (http://citifluor.com/) mounting medium. Positively hybridized cells were imaged using an Olympus BX51 epifluorescence microscope at $\times 1000$ magnification using an Olympus UPlanFL N 100X objective fitted with a gray scale camera. Individual color channels were merged using Fiji 2.0.0-rc-19 (http://fiji.sc).

\section{Electron cryomicrography}

Cells were concentrated by centrifuging $2 \times 1 \mathrm{ml}$ aliquots of culture at $10000 \mathrm{~g}$ for $5 \mathrm{~min}$ and were resuspended in $0.15 \mathrm{ml}$ supernatant. Twenty microliters of a concentrated cell suspension was mixed with BSA-treated colloidal gold and applied to R2/2 copper quantifoil EM grids (Quantifoil Micro Tools, Großlöbichau, Germany). Excess liquid was blotted with filter paper and plunged into a liquid ethane/ propane mixture (Tivol et al., 2008) either manually or using a Vitrobot (FEI Company, Hillsboro, OR, USA). Images were recorded using an FEI G2 (FEI Company) $300 \mathrm{kV}$ field emission gun electron microscope equipped with a Gatan imaging filter and either a $4 \times 4 \mathrm{k}$ UltraCam or a K2 Summit counting direct electron detector camera (Gatan, Pleasanton, CA, USA). Data were collected using digital micrograph and UCSFtomo software (Zheng et al., 2007). Cumulative electron doses of $\sim 160 \mathrm{e}^{-} \AA^{-2}$ or less were used for each tilt series. The images were processed using the IMOD software package (Kremer et al., 1996).

\section{Izimaplasma enrichment media}

Izimaplasma were enriched from Hydrate Ridge methane seep sediment sample \#5579 using a media composed of artificial seawater amended with glucose $\left(5 \mathrm{gl}^{-1}\right)$, yeast extract $\left(0.2 \mathrm{gl}^{-1}\right)$ and the antibiotics ampicillin and vancomycin (see Supplementary Methods for details of the media recipe). The media was reduced by adding a small amount $(\sim 0.2 \mathrm{ml})$ of $\mathrm{Ti}$ (III)-nitrilotriacetic acid in a bottle under 80:20 $\mathrm{N}_{2}: \mathrm{CO}_{2}$ headspace. Ampicillin and Vancomycin were added to the anaerobic, reduced media to a final concentration of 200 and $1 \mu \mathrm{g} \mathrm{ml}^{-1}$. Enrichment bottles $(30 \mathrm{ml}$ media in $70 \mathrm{ml}$ serum bottles) were incubated at $10^{\circ} \mathrm{C}$ under $200 \mathrm{kPa}$ of $\mathrm{N}_{2}$ headspace.

\section{Community profiling}

DNA was extracted from the enrichment cultures using the MO BIO PowerSoil DNA isolation kit (MO BIO Laboratories Inc.; cat. no. 12888-50) according to the manufacturer's instructions. Sequencing was performed using the Illumina MiSeq platform according to the earth microbiome project specification; see Mason et al. (2015) for a full description of the sequencing and bioinformatics processing of the data.

\section{Data availability}

The genome sequences for Izimaplasma sp. HR1 and HR2 are available on NCBI as CP009415 and JRFF01000000, respectively. The metagenomic data is available on NCBI under the bioproject accession PRJNA290197.

\section{Results}

Phylogeny of methane seep Tenericutes

Metagenomic assembly and binning resulted in two distinct, highly complete population genome bins, designated HR1 and HR2, that were affiliated with the Tenericutes based on phylogenetic analysis of the $16 \mathrm{~S}$ rRNA gene and a concatenated protein alignment of 38 universally distributed single-copy genes (hereafter referred to as a genome tree; Figure 1; Supplementary Figure S1; Supplementary Table S1). Initial placement of the $16 \mathrm{~S}$ rRNA gene using the SILVA 119 database and ARB parsimonious insertion tool revealed that the genomes were members of a clade known as 'NB1-n' (clade referred to as RF3 in the greengenes database) that were comprised solely of environmental 16S rRNA sequences (Supplementary Figure S2). 'NB1-n' is defined as an order-level group in the SILVA 119 database that contains sequences derived from mesophilic anaerobic digesters, landfill, animal rumen and saline sediments (Supplementary Figure S2). The genome tree places HR1 and HR2 as a sister group of the Acholeplasmatales with $H$. contractile and $T$. sanguinis branching more deeply (Figure 1). Realignment of the 16S rRNA gene using the protocol of the Ribosomal Database Project (RDP) and phylogenetic construction of clade 'NB1-n' with cultured Tenericutes, some Firmicutes and Actinobacteria supported the placement of clade 'NB1-n' as a sister group of the Acholeplasmatales; however, in 


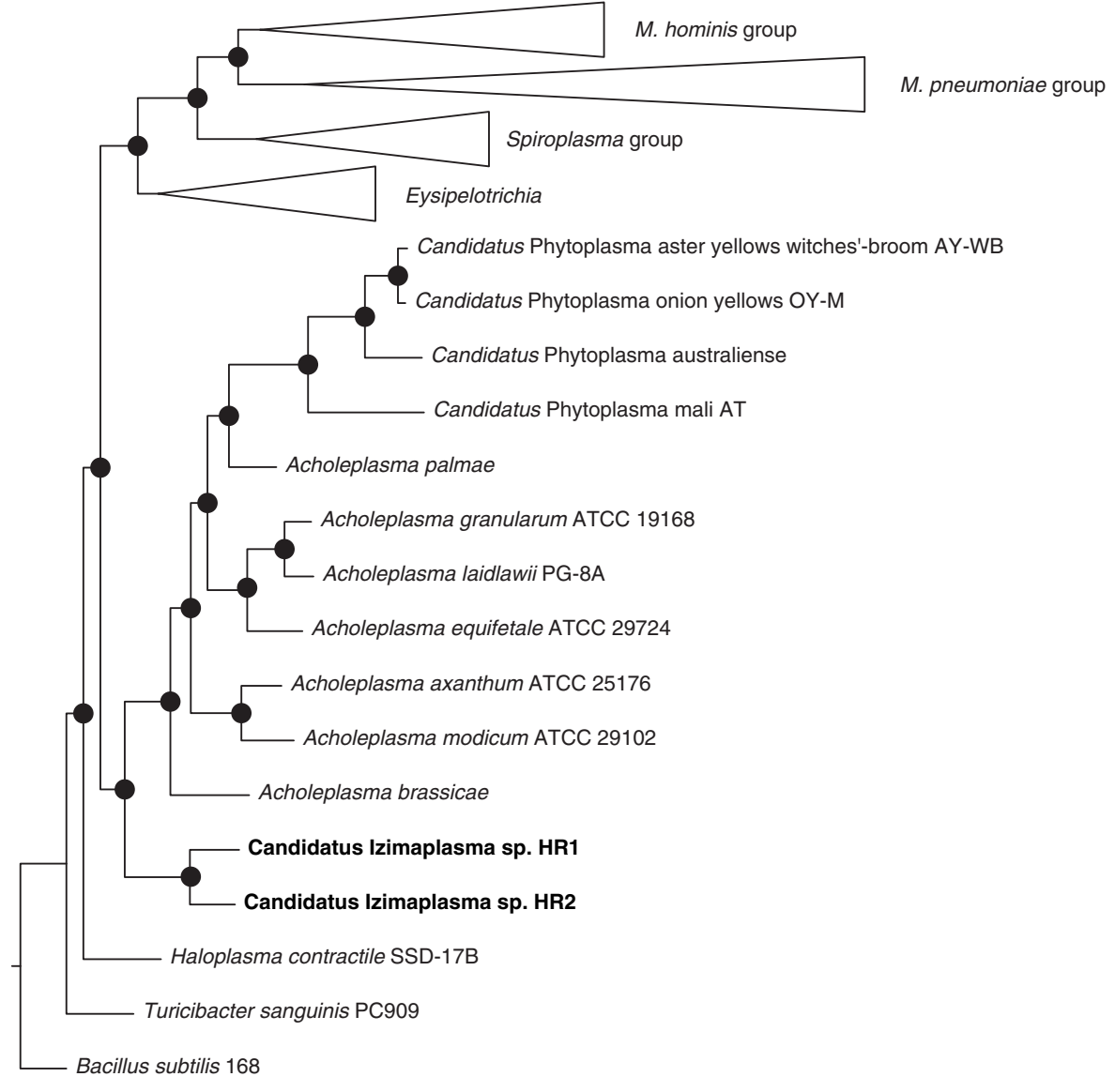

0.3

Figure 1 Maximum likelihood phylogenetic tree of Tenericutes and the firmicute class Eysipelotrichia constructed from the concatenated alignment of 38 single-copy genes; Bacillus subtilis was used as the outgroup. Collapsed wedges represent monophyletic groups of genomes. Nodes with greater than $95 \%$ bootstrap support are annotated with a black circle. Scale bar indicates substitutions per site.

this tree $H$. contractile and T. sanguinis branch within clade 'NB1-n' as defined by SILVA 119 (Figure 2).

The phylum Tenericutes was defined in part by using non-ribosomal protein markers that showed that members of the Mollicutes were phylogenetically distinct from the Firmicutes (Ludwig and Schleifer, 2005). Further phylogenetic analysis of HR1 and HR2 using the beta subunit of the RNA polymerase $(r p o B)$ and elongation factor $\mathrm{Tu}$ (EF-Tu) placed HR1 and HR2 basal to members of the acholeplasmas (Supplementary Figure S3; Supplementary Figure S4). The broader phylogeny of RpoB revealed that the Mollicutes are polyphyletic; members of the genus Mycoplasma branch deeply, and separate from the Firmicutes, in agreement with previous phylogenetic analysis (Ludwig and Schleifer, 2005); while members from the Acholeplasma, Entomoplasma and Candidatus Phytoplasma branch within the Firmicutes. The EF-Tu phylogeny places the Mycoplasma and Acholeplasma in two distinct clades, separated by members of the Erysipelotrichia and some bacilli. H. contractile and $T$. sanguinis branch together in both the RpoB and EF-Tu trees in support of their close association in the genome tree and 16S rRNA gene tree (Figure 1; Figure 2; Supplementary Figure S3; Supplementary Figure S4).

Based on the unique phylogenetic position of these two genomes, we propose the names Candidatus 'Izimaplasma sp. HR1' and Candidatus 'Izimaplasma sp. HR2' (Izima-, Greek for sediment; -plasma, formed or molded, refers to the lack of cell wall) for the two genome sequences presented here.

\section{Genome-based metabolic reconstruction of}

Izimaplasma

The two Candidatus 'Izimaplasma' genomes (referred to as Izimaplasma sp. HR1 and Izimaplasma sp. HR2 hereafter) are comparatively larger than most other Mollicutes, at 1.8 and $2.1 \mathrm{Mbp}$ (Supplementary Table S1; Supplementary Figure S6), however, they are of similar size to some members from the Acholeplasmatales, which are phylogenetically the closest recognized Tenericute clade. Like the Acholeplasmateles, the Izimaplasma genomes use the bacterial genetic code with UGA as a stop codon rather than encoding for tryptophan (Supplementary Figure S7). Both genomes contain hallmarks of genome streamlining, including a 


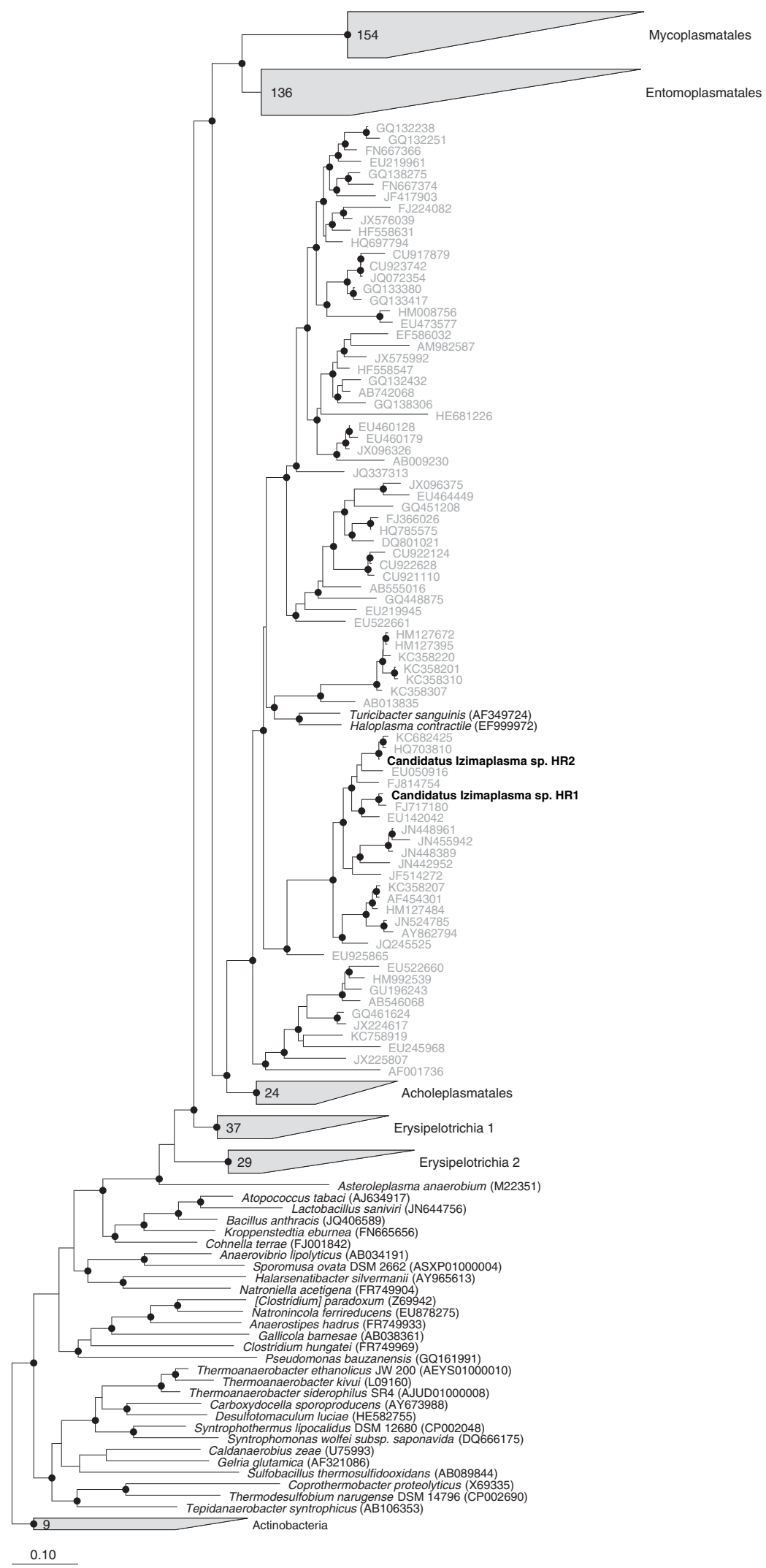

Figure 2 Maximum likelihood phylogenetic tree of 16S rRNA gene sequences from cultured Tenericutes, Erysipelotrichia, some other Firmicutes representatives and some Actinobacteria used as the outgroup. Gray wedges represent monophyletic groups of a particular taxonomy. In this tree the class Erysipelotrichia are split into two groups, labeled 1 and 2. Sequences belonging to clade 'NB1-n' are shown in gray. All sequences are labeled with their NCBI accession numbers. Nodes with greater than $70 \%$ bootstrap support are labeled with a black circle. Scale bar represents substitutions per site. 
high protein coding percentage (Supplementary Figure S6) and a small number of repetitive elements, with Izimaplasma sp. HR1 containing a single multi-copy transposon, which facilitated the highly contiguous metagenomic assembly and genome finishing.

Reconstruction of metabolic pathways in the genomes resulted in a predictive model of the central carbon metabolism reliant on fermentation of simple sugars, similar to other Tenericutes (Figure 3). The two Izimaplasma genomes contained a complete set of genes to perform the Embden-Meyerhof-Parnas
(EMP) pathway for glycolysis and a complete pentose phosphate pathway. The tricarboxylic cycle was incomplete in the Izimaplasma genomes, with lactate being the probable end point of fermentation (Figure 3). Both Izimaplasma genomes predicted the ability to metabolize glucose, sucrose and maltose as carbon sources. In addition, Izimaplasma sp. HR1 has the genes to utilize fructose and trehalose, while Izimaplasma sp. HR2 contained the genes to metabolize galactose and cellulose (Figure 3). Both genomes also contained the arginine dihydrolase pathway that has been previously described in

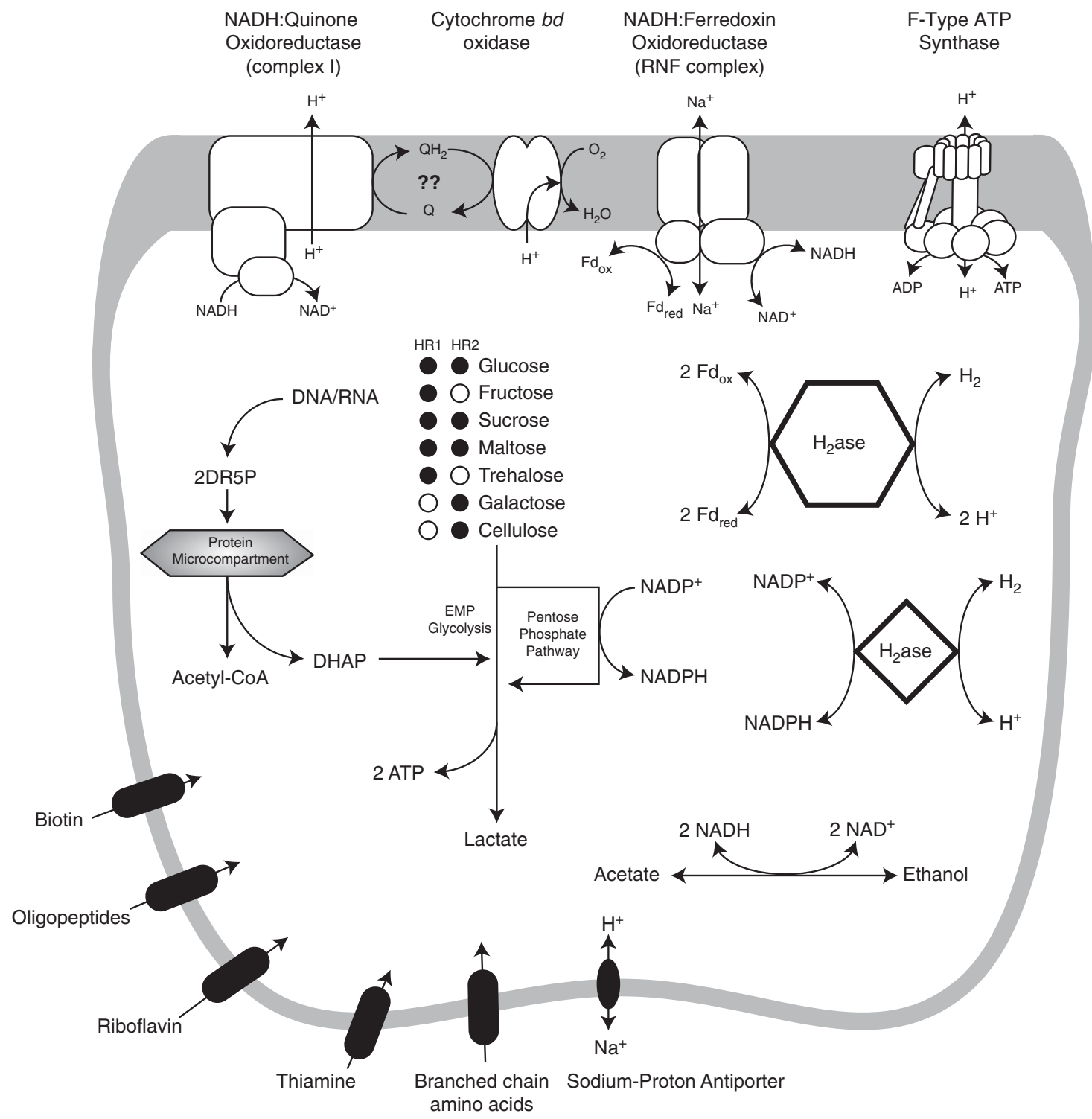

Figure 3 Model predictions of the central metabolism inferred from Izimaplasma genomes. Both genomes illustrate the potential for metabolizing a variety of simple sugar compounds that feed into the Embden-Meyerhof-Parnas glycolysis pathway (symbolized by black circles). Reducing equivalents (NADH) generated through glycolysis can be oxidized either by the conversion of acetate to ethanol, using a membrane-bound, sodium-pumping NADH:Ferredoxin oxidoreductase (RNF complex) or by a proton-pumping NADH:Quinone oxidoreductase (complex I). Both complex I and the cytochrome bd oxidase interact with the quinone pool, however no quinone synthesis genes were identified in the genome. Two types of hydrogenases act in catabolism to regenerate oxidized ferredoxin, or in anabolism to regenerate NADPH used during lipid and nucleotide synthesis. Izimaplasma sp. HR2 contains a protein microcompartment that links the degradation of DNA or RNA to the production of acetyl-CoA and intermediates of glycolysis. 2DR5P, 2-deoxy-D-ribose 5phosphate; DHAP, dihydroxyacetone phosphate. 
Mollicutes as a source of ATP through the oxidation of arginine to ammonia (Razin, 2006).

Reducing equivalents generated by anaerobic fermentation have the potential to be converted to hydrogen by Izimaplasma. Both of the Izimaplasma genomes contain two types of iron hydrogenases along with hydrogenase maturation genes (hydEFG). The first hydrogenase couples with ferredoxin and could be used to remove excess reducing equivalents during anaerobic fermentation (Figure 3). The second hydrogenase is linked with NADP and suggests that it may generate NADPH for the production of biomolecules (Figure 3; Malki et al., 1995). Hydrogenases are not present in mollicute genomes but are found in Erysipelotrichales, $H$. contractile and T. sanguinis (Supplementary Figure S8).

Both Izimaplasma genomes contained homologs of the sodium translocating NADH:Ferredoxin oxidoreductase (RNF complex) and the proton translocating NADH:Quinone oxidoreductase (complex I). The RNF complex has been described from the genomes of some Acholeplasmatales and many of the Erysipelotrichales; however, complex I has not been found in any previously described mollicute (Supplementary Figure S8). The Izimaplasma genomes encoded three copies of the RNF complex, two of which contained the same operon structure (rnfCDGEAB) seen in clostridium species (Biegel et al., 2011). The third copy of the rnf gene cluster lacked the $r n f C$ subunit and instead contained homologs of cytochrome $b d$ oxidase $(a p p C D)$. RnfC is an iron-sulfur, flavin mononucleotide containing protein that is responsible for oxidizing NADH (Reyes-Prieto et al., 2014), without this subunit this copy of the RNF complex may not be functional or may need to be compensated by the RnfC subunit found in the other two operons.

Phylogenetic reconstruction of the cytochrome $b d$ oxidase protein AppC revealed that the closest relative of the Izimaplasma cytochrome $b d$ oxidase was to Methanosarcina acetivorans, a member of the archaeal order Methanosarcinales (Supplementary Figure S9). However, the low $(\sim 30 \%)$ percentage identity and long branch length between the two proteins suggests that this was not due to a recent horizontal gene transfer between these two organisms. A search of other AppC in all of the metagenomic contigs failed to identify a more closely related AppC than the M. acetivorans protein, which suggests that Izimaplasma has not acquired these genes through a recent lateral gene transfer from other members of the sediment community.

The subunits for complex I were split into two separate operons, with the majority of the subunits (nuoKNLHBCD) comprising the P- and Q-modules found adjacent to a sodium-proton antiporter (mnhEFGB) and the subunits of the N-module (nuoEFG) found in a separate operon. Four subunits (nuoAIJM) from the P- and Q-modules could not be identified, however the adjacent sodium-proton antiporter is the evolutionary progenitor of the P-module of complex I (Moparthi and Hägerhäll, 2011), it is possible that these genes function as part of complex I in Izimaplasma. Comparisons of the complex I subunits to previously sequenced genomes showed highest similarities to members of the Thermotogae and Thermoanaerobacteriales. The larger operon containing nuoKNLHBCD were most closely related to Marinitoga piezophilla (phylum Thermotogae; average $60 \%$ amino acid identity), which also contains the same gene order as the operon in Izimaplasma, whereas the operon containing the N-module (nuoEFG) were most closely related to Mahella australiensis (phylum Firmicutes, order Thermoanaerobacteriales).

In other organisms, complex I and cytochrome $b d$ oxidase interact with the quinone pool, however Izimaplasma lacked a complete quinone synthesis pathway. Both Izimaplasma genomes contain the non-mevalonate (MEP/DOXP) pathway to generate the quinone precursors Isopentenyl-PP and Dimethylallyl-PP, but do not contain the rest of the pathway. Complex I and cytochrome $b d$ oxidase may be nonfunctional without internal quinone production, an alternative electron carrier, or an external source of quinone.

Protein microcompartment for nucleotide metabolism Both Izimaplasma genomes contained similar metabolic potential, however Izimaplasma sp. HR2 contained an additional large operon, comprised of 14 genes that appeared to encode a protein microcompartment. Bacterial microcompartment genes have been identified in many microorganisms and appear to be horizontally transferred (Kerfeld et al., 2010). These protein-based compartments encapsulate enzymes and cofactors to promote specific metabolic pathways including carbon fixation, 1,2-propanediol, ethanol and ethanolamine metabolism and are found in $\sim 20 \%$ of sequenced genomes (Stojiljkovic et al., 1995; Seedorf et al., 2008; Kerfeld et al., 2010; Erbilgin et al., 2014). With the exception of carbon fixation, the other metabolic pathways encapsulated within microcompartments produce aldehyde intermediates that may be toxic to the cell. It has been proposed that encapsulating these reactions within a microcompartment protects the cell from these intermediates and allows for a more efficient metabolism of these compounds (Kerfeld et al., 2010). Izimaplasma sp. HR2 contained a 10-kbp operon containing structural genes for generating a microcompartment plus a number of catalytic genes (Figure 4). An aldehyde dehydrogenase was found in this operon that suggests that Izimaplasma sp. HR2 also uses a microcompartment for detoxification purposes. However, examination of the other catalytic genes in the microcompartment-associated operon pointed to the possibility of an alternate, previously 


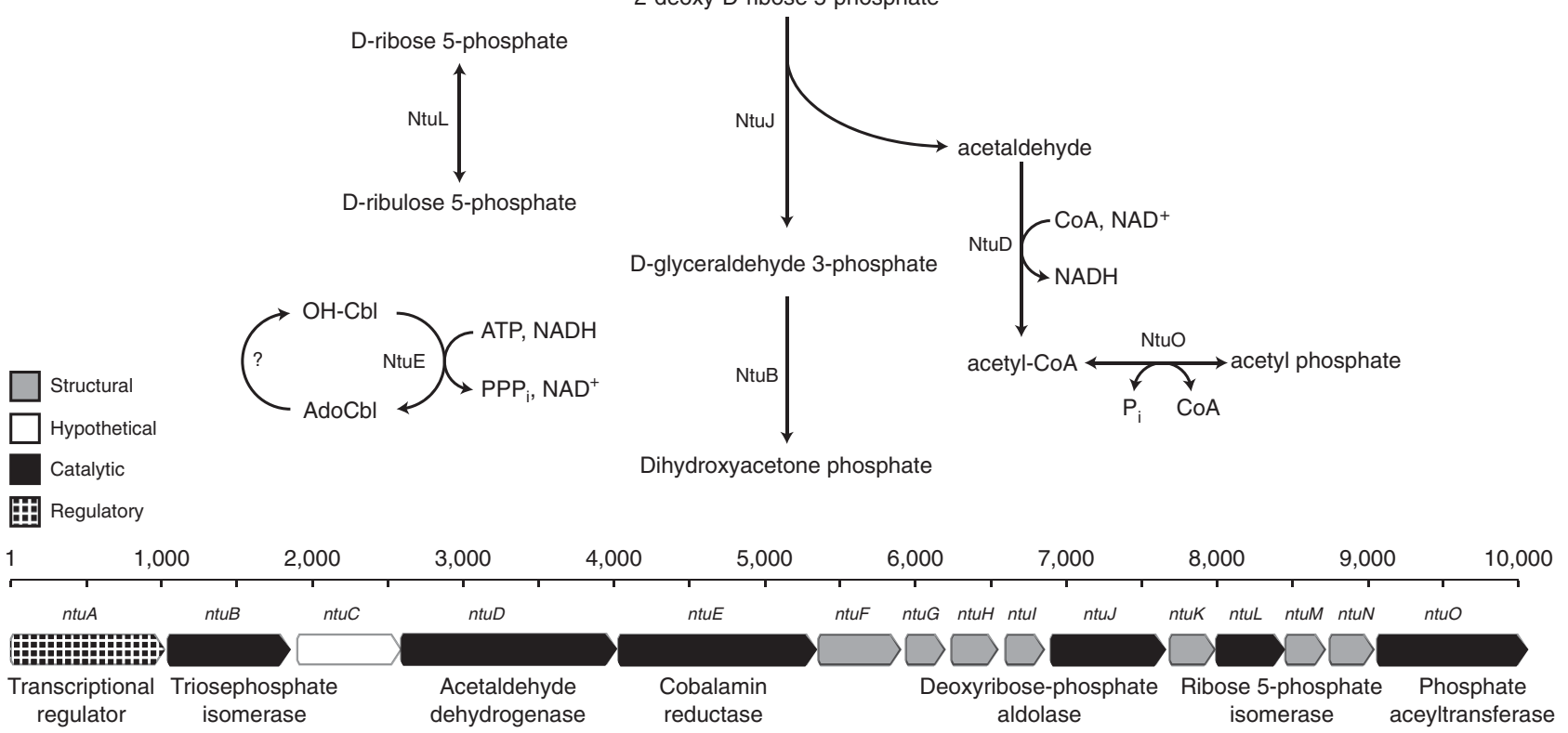

Figure 4 Proposed model of DNA/RNA degradation by the protein microcompartment found in Izimaplasma sp. HR2. The operon encoding the structural and catalytic genes of this microcompartment, which we propose to call the nucleotide utilizing operon (ntu), is shown below. The reactions catalyzed by this operon are shown above and labeled with the protein that catalyzes each reaction. Two proteins for cofactor recycling (NtuE, NtuO) are also found; however, the protein requiring a cobalamin cofactor is unknown (represented by ?). AdoCbl, adenosylcobalamin; OH-Cbl, hydroxocobalamin.

undescribed metabolism related to nucleic acid degradation. A complete pathway was predicted that would enable strain HR2 to convert 2-deoxy-Dribose 5-phosphate, an intermediate in nucleotide metabolism to dihydroxyacetone phosphate, an intermediate in glycolysis. The first step in this reaction, the conversion of 2-deoxy-D-ribose 5phosphate to D-glyceraldehyde 3-phosphate produces acetaldehyde as a byproduct (Figure 4). Acetaldehyde can then be converted to acetylCoA using the acetaldehyde dehydrogenase $(n t u D)$ and utilized along with dihydroxyacetone phosphate as carbon and energy sources. Two genes in the Izimaplasma sp. HR2 microcompartment operon (ntuEO) could be utilized for the purposes of recycling cofactors vitamin B12 and Coenzyme A (CoA), which is consistent with previous reports that microcompartments contain their own pool of cofactors (Huseby and Roth, 2013). Despite only being present in Izimaplasma sp. HR2 genome, the protein microcompartment operon does not appear to add novel metabolic functionality as the ability to metabolize 2-deoxy-D-ribose 5 -phosphate is also present in the Izimaplasma sp. HR1 genome. Furthermore, homologs of phosphate acetyltransferase $(n t u O)$ and deoxyribosephosphate aldolase (ntu) genes are found in the majority of mollicute genomes (Supplementary Figure S8) but not associated with structural microcompartment genes. Although these genes appear consistent with the degradation of nucleotides within the microcompartment, cultivation of a representative of HR2 may be required to better understand the function of this ultrastructural feature.

\section{Visual identification and enrichment cultivation of Izimaplasma}

The occurrence of members of clade 'NB1-n' in the \#5579 incubation was assessed by FISH microscopy using a newly designed oligonucleotide probe 'Izzy659' targeting members of this clade (Supplementary Figure S2). A small number of coccoid-shaped cells (0.6-1 $\mu \mathrm{m}$ diameter) were positively hybridized in the seep sediment, observed either as single cells or doublets (Figure 5). To try and culture this organism, we used the predicted metabolism and phenotype from the HR1- and HR2annotated genomes as a guide for designing enrichment medium, adding simple sugars (for example, glucose) as a carbon source and cell wall acting antibiotics to select for members of the Tenericutes. After a 6-week incubation at $10^{\circ} \mathrm{C}$, the community was dominated by two cell types: small coccoid cells (0.5-1.0 $\mu \mathrm{m}$ diameter) that positively hybridized to the 'NB1-n'-specific probe, and larger coccoid cells that only hybridized to the general bacterial probe (Figure 5). This community composition remained stable for over five passages through new enrichment media and isolation attempts are still ongoing. Illumina $16 \mathrm{~S}$ rRNA gene sequencing (iTAG) confirmed our FISH observations, with $\sim 60 \%$ of the recovered reads in the incubations assigned to clade 'NB1-n' (Supplementary Figure S5). There were three 'NB1-n' operational taxonomic units 
defined from the iTAG data, one of which was dominant, accounting for $90 \%$ of the 'NB1-n' sequences and was $98 \%$ identical to the region of the 16S rRNA gene recovered from the HR1 genome bin. Electron cryotomography of the enrichment culture confirmed the presence of coccoid cells lacking a cell wall, with a membrane architecture comparable to the Mollicute, Mycoplasma pneumonia (Figure 6). Representative cells of 'NB1-n' in the enrichment analyzed by electron cryotomography were $1 \mu \mathrm{m}$ in diameter and devoid of any discernable intracellular structure.

\section{Discussion}

Members of the class Mollicutes are some of the smallest self-replicating organisms discovered in nature (Razin, 2006). Currently described isolates have been recovered from a variety of plant and animal hosts, and many members are important to veterinary and agricultural sciences as pathogens (Razin et al., 1998; Razin, 2006). Environmental clades, identified solely through $16 \mathrm{~S}$ rRNA gene diversity studies, have been affiliated with the class Mollicutes. Sequences from one of these clades,
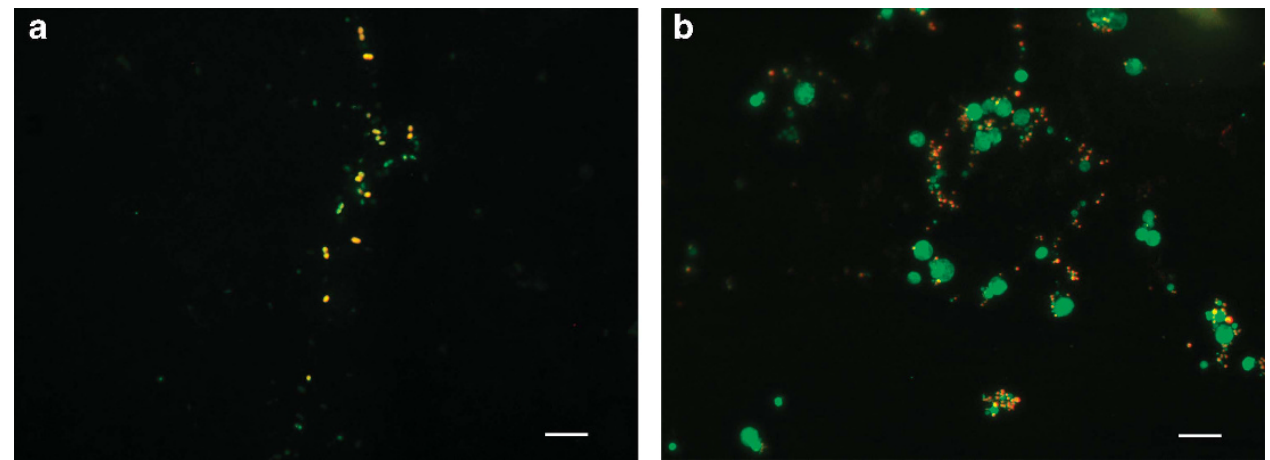

Figure 5 Fluorescence in situ hybridization (FISH) micrograph of microorganisms recovered from a methane seep sediment incubation. Cells targeted by the general bacterial probe, EUB338, are shown in green (FITC); cells targeted by the specific probe for Izimaplasma (Izzy659) are shown in yellow (combined FITC and Cy3 fluorescence). The scale bar in both images is $10 \mu \mathrm{m}$. (a) FISH image of microorganisms from the initial sediment sample used for the Izimaplasma enrichment. (b) Microbial diversity after 6 weeks of cultivation in glucose-amended enrichment media.
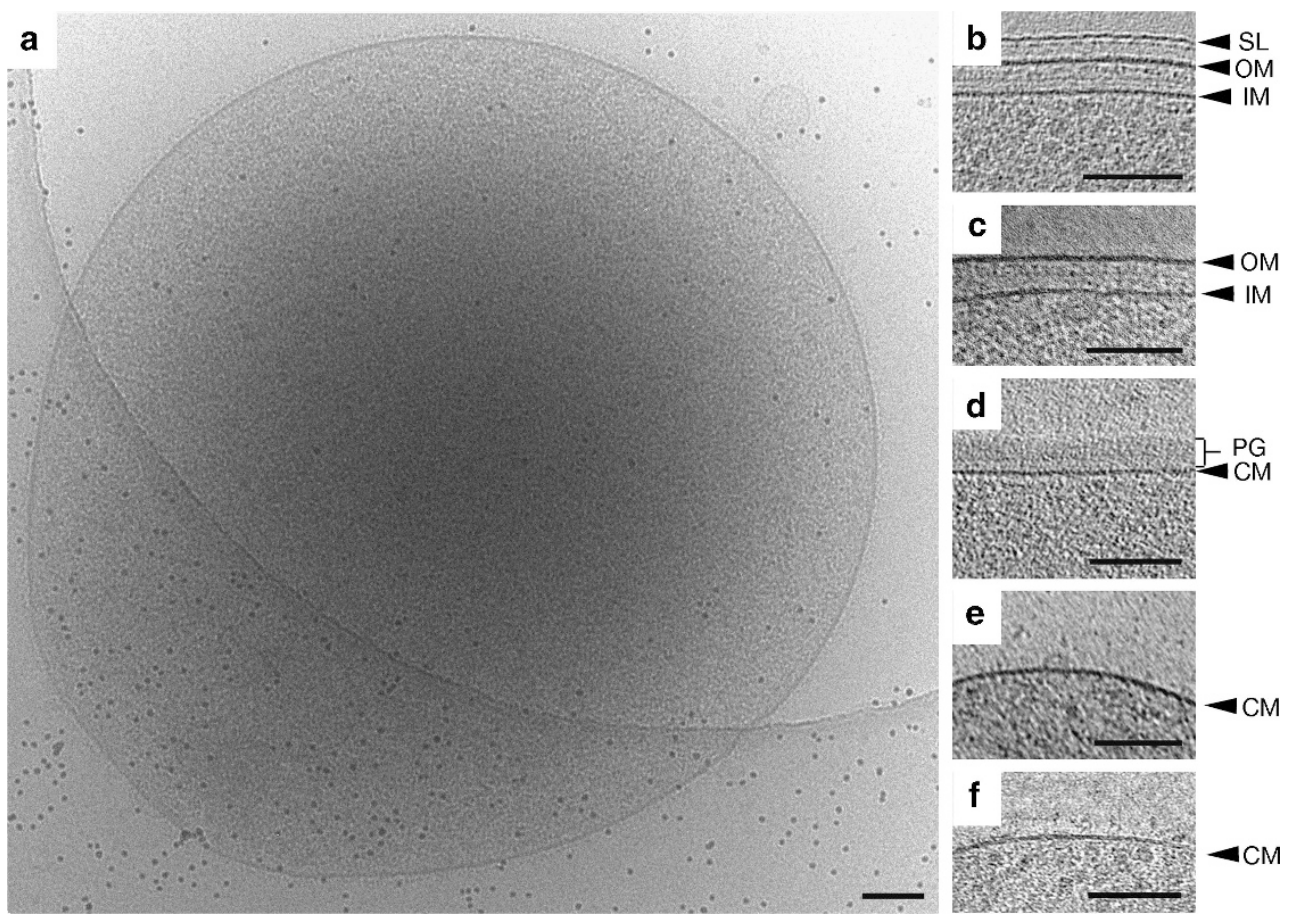

Figure 6 (a) Electron cryomicrograph of an Izimaplasma cell. (b-f) Bacterial cell envelope architectures from slices of cryotomograms. (b) Gram-negative cell wall with S-layer: Caulobacter crescentus; (c) Gram-negative cell wall without S-layer: Vibrio cholera; (d) Grampositive cell wall: Listeria monocytogenes; (e) cell-wall less: Mycoplasma pneumonia; (f) cell-wall less: Izimaplama. CM, cell membrane; IM, inner membrane; OM, outer membrane; PG, peptidoglycan; SL, S-layer. Scale bars, $100 \mathrm{~nm}$. 
'NB1-n', have been previously reported from anaerobic digesters, hypersaline microbial mats, marine sediments and rumen (Supplementary Figure S2). These environments, with the exception of rumen, are distinct from the plant- and animal-affiliated habitats that are well known environments for Mollicutes and raises the possibility that members of clade 'NB1-n' are free-living rather than host-associated organisms. Our work here using a combination of metagenomics and enrichment cultivation confirms the free-living nature of the Tenericutes-associated Izimaplasma, demonstrating that these microorganisms are capable of growth under cold, anaerobic conditions in the absence of a eukaryotic host.

The taxonomy of Mollicutes has been a source of debate. Mollicutes are currently classified as the sole class within the phylum Tenericutes based on their unique phenotypic properties and the phylogeny of non-ribosomal phylogenetic markers (Ludwig et al., 2009). Conversely, phylogenetic analysis of the $16 \mathrm{~S}$ rRNA gene, 23S rRNA gene and a concatenated alignment of ribosomal proteins place the Mollicutes within the phylum Firmicutes, closely associated with the firmicute class Erysipelotrichia (Davis et al., 2013; Yutin and Galperin, 2013). The observation that Mollicutes do not share a common root with the Firmicutes for some non-ribosomal proteins (Ludwig and Schleifer, 2005) is not fully supported with current genomic data (Supplementary Figures S3 and S4). The RpoB phylogeny places Mycoplasma near the base of the bacterial tree, however the Acholeplasma branch with the Firmicutes. It has been proposed that the acholeplasmas were the first Mollicutes to diverge from an ancestral firmicute and that the Mycoplasma diverged through extensive genome reduction (Brown et al., 2011). The positioning of the Mycoplasma near the base of the RpoB tree may be the result of accelerated evolution that can occur when bacteria become dependent on host organisms that obfuscates molecular phylogeny analysis (McCutcheon and Moran, 2012). Despite the variability of phylogenetic placement of the Mollicutes, the Izimaplasma genomes branched consistently with members of the Acholeplasmatales. The next most phylogenetically related organisms, $H$. contractile and $T$. sanguinis, consistently branched together when using ribosomal or nonribosomal genes, which suggest that they may be more closely related than suggested by their current taxonomic classifications. Visual identification of Izimaplasma cells using FISH and electron microscopy showed that Izimaplasma were not associated with eukaryotes and carried the defining membrane architecture of all previously studied Tenericutesdistinct from the Gram-positive cell wall found within members of the Firmicutes (Figures 5 and 6).

The size and metabolic completeness of the Izimaplasma genomes is comparable to free-living streamlined marine bacteria like Prochlorococcus and Pelagibacter (Supplementary Figure S6). In contrast, bacteria that are more reliant on host organisms typically undergo genome reduction through the removal of core metabolic properties, and also tend to accumulate pseudogenes and have a higher overall percentage of non-coding DNA (reviewed in Giovannoni et al., 2014). There are a number of unique metabolic features that distinguish Izimaplasma from the currently described hostassociated Mollicutes (Supplementary Figure S8). Homologs to the Izimaplasma hydrogenases and the RNF complex were only detected in related bacteria including $H$. contractile and T. sanguinis as well as some representatives from the Erysipelotrichia (Supplementary Figure S8). The presence of cytochrome $b d$ oxidase and complex I in Izimaplasma is unique among all currently described Mollicutes (Supplementary Figure S8). The Izimaplasma genes and their closest homologs from archaea, Thermotogae and Thermoanaerobacteriales showed lowsequence identity suggesting that these genes have not been recently laterally transferred, despite Izimaplasma being recovered from seep sediments dominated by methanotrophic ANME archaea. One possible explanation for these observations is that the ancestor of current Izimaplasma accumulated membrane-bound electron complexes from multiple donor organisms. It is also possible that a single, as yet unsequenced microorganism, was the single donor to Izimaplasma.

The presence of hydrogenases and electron transport complexes may provide Izimaplasma with multiple means of cycling redox-active electron carriers like ferredoxin and $\mathrm{NAD}(\mathrm{P}) \mathrm{H}$. The presence of cytochrome $b d$ oxidase and complex I suggests a simplified electron transport chain in Izimaplasma, where electrons from NADH are transferred to the quinone pool and are subsequently utilized by cytochrome $b d$ oxidase to reduce oxygen (Figure 3). This model has implications for the potential function of the F-Type ATPase in Izimaplasma, as in many Mollicutes, the F-type ATPase functions to maintain a proton gradient by hydrolyzing ATP, rather than through ATP generation (Pollack et al., 1997). In Izimaplasma, the presence of multiple membrane-bound ion pumping complexes could drastically change how Izimaplasma generates ATP. The activity of these ion pumping complexes may allow for a sufficient proton gradient for the ATPase to generate ATP.

One inconsistency with this model is the absence of a complete quinone synthesis pathway in the Izimplasma genomes. If indeed this predicted complex I and $b d$ cytochrome oxidase are functional in Izimaplasma, a source of quinone must be acquired from an external source- perhaps passaged through associations with other organisms in the methane seep microbial community. Membrane vesicles, which are produced by many Gramnegative bacteria (Beveridge, 1999) have been shown to fuse with mollicute membranes (Grant and McConnell, 1973) and could represent a mechanism to 
deliver quinone to Izimaplasma (Bergsma et al., 1982). Alternatively, Izimaplasma may contain an, as yet undescribed, pathway to synthesize quinone or potentially use an alternative membrane-soluble electron carrier. The expression and functionality of these enzymes can only be determined from further biochemical analysis; however, the genetic evidence does suggest that these are not pseudogenes. There are no internal stop codons or frameshifts in either operon and the Izimaplasma-associated cytochrome bd oxidase contains characteristic amino acids for quinone and heme binding (Zhang et al., 2004; Mogi et al., 2006; Yang et al., 2007). The selective pressure for Izimaplasma to retain these electron transport complexes and their physiological role in these organisms can only be speculated. In model organisms, such as Escherichia coli, cytochrome bd oxidase functions under microaerophilic conditions to protect the anaerobic metabolism from oxygen poisoning (Borisov et al., 2011). It may be that Izimaplasma are exposed to variable levels of oxygen in situ within the seep environment, where bioturbation and methane bubble ebullition can mix oxygenated seawater into the shallow seafloor sediments. Here the cytochrome $b d$ complex may serve as an efficient way for Izimaplasma to protect itself from oxygen and generate proton motive force to generate extra ATP.

The most striking difference between the two genomes was the presence of a microcompartment operon in Izimaplasma sp. HR2. Analysis of the enzymatic genes in this operon suggested that the compartment is used for the efficient metabolism of purines and pyrimidines. This proposed metabolism is unique among currently known microcompartments but there are similar features as the reaction generates acetaldehyde, which has been proposed in other microcompartments to be a toxic intermediate that requires sequestering from the cytoplasm (Kerfeld et al., 2010). The presence of the microcompartment suggests that Izimaplasma sp. HR2 may be more efficient at metabolizing nucleic acids. A comparison with the Izimaplasma sp. HR1 genome showed that the complement of purine and pyrimidine metabolic genes is identical between the two genomes, which suggests that Izimaplasma sp. HR1 is also capable of degrading nucleic acids but this may occur at a slower rate. Electron cryomicroscopy did not reveal any discernable microcompartments in cells from the enrichment culture, however the dominant operational taxonomic unit in this mixed culture was closely related to Izimaplasma sp. HR1, which lacks the microcompartment genes. Additional genome sequencing is needed to assess how widespread these microcompartment genes are within the Iziamplasma.

The deep phylogenetic placement of Izimaplasma, basal to the Acholeplasmatales, may warrant the creation of a novel class of free-living wall-less bacteria within the phylum Tenericutes. These organisms could represent an intermediate in the reductive evolution from Firmicutes to Mollicutes. The lack of an obvious host organism suggests that cell-wall loss may have occurred before symbiotic relationships with Eukaryotes were formed. However, recent discovery of symbiotic Mollicutes of Fungi that have retained their cell wall suggests that cell-wall loss has occurred multiple times (Desirò et al., 2014; Naito et al., 2015; Torres-Cortés et al., 2015). There is also the possibility that Izimaplasma have non-obligate symbiotic relationships with micro-eukaryotes that were undetected in the incubations or sediment samples analyzed. The successful enrichment and passage of Izimaplasma relatives from methane seep sediment incubations suggests that culturing efforts and sequencing of environmental DNA from marine sediments may result in pure culture isolates for further taxonomic classification and physiological experiments.

The metabolic reconstruction and enrichment cultivation results indicate that Izimaplasma do not directly take part in the methane and sulfur cycles that are dominant in methane seeps. Instead, members of the Izimaplasma, representing a rare member of the seep microbial community, appear to be heterotrophs engaging primarily in fermentative metabolism, consisting of simple sugars, small organic acids, arginine and possibly nucleotides generated during the degradation of organic matter. These genomic predictions enabled the design of anaerobic culture media to selectively enrich for Izimaplasma from methane seep sediments. Unlike previously described mollicute genomes, Izimaplasma contain homologs to cytochrome $b d$ and to complex I that may form a simplified electron transport chain. Their predicted role in the community is likely in the fermentation of products from the degradation of organic matter to produce lactate and possibly other small molecules such as acetate or ethanol, which in turn may be utilized by other members of the methane seep microbial community.

\section{Conflict of Interest}

The authors declare no conflict of interest.

\section{Acknowledgements}

This work is funded by the Gordon and Betty Moore Foundation through Grant GBMF3780 and the US Department of Energy, Office of Science, Office of Biological Environmental Research under award numbers DESC0003940 and DE-SC0010574 (to VJO). Additional support was provided by Caltech's Center for Environmental Microbial Interactions and the Howard Hughes Medical Institute. We thank D Smith, S Scheller, S Zinder, J Hemp and D Newman for helpful discussions and M Imelfort for bioinformatics assistance. GWT was supported by an ARC Queen Elizabeth II fellowship (ARC-DP1093175). 


\section{References}

Antunes A, Alam I, El Dorry H, Siam R, Robertson A, Bajic VB et al. (2011). Genome sequence of Haloplasma contractile, an unusual contractile bacterium from a deep-sea anoxic brine lake. J Bacteriol 193: 4551-4552.

Antunes A, Rainey FA, Wanner G, Taborda M, Pätzold J, Nobre MF et al. (2008). A new lineage of halophilic, wall-less, contractile bacteria from a brine-filled deep of the Red Sea. J Bacteriol 190: 3580-3587.

Bergsma J, Meihuizen KE, Van Oeveren W, Konings WN (1982). Restoration of NADH oxidation with menaquinones and menaquinone analogues in membrane vesicles from the menaquinone-deficient Bacillus subtilis aroD. Eur J Biochem 125: 651-657.

Beveridge TJ. (1999). Structures of gram-negative cell walls and their derived membrane vesicles. J Bacteriol 181: 4725-4733.

Biegel E, Schmidt S, González JM, Müller V. (2011). Biochemistry, evolution and physiological function of the Rnf complex, a novel ion-motive electron transport complex in prokaryotes. Cell Mol Life Sci 68: 613-634.

Borisov VB, Gennis RB, Hemp J, Verkhovsky MI. (2011). The cytochrome bd respiratory oxygen reductases. Biochim Biophys Acta 1807: 1398-1413.

Brown DR, May M, Bradbury JM, Johansson K-E. (2011). Class I. Mollicutes. In: Krieg NR, Staley JT, Brown DR, Hedlund BP, Paster BJ, Ward NL et al. (eds). Bergey's Manual of Sstematic Bacteriology: The Bacteroidetes, Spirochaetes, Tenericutes (Mollicutes), Acidobacteria, Fibrobacteres, Fusobacteria, Dictyoglomi, Gemmatimonadetes, Lentisphaerae, Verrucomicrobia, Chlamydiae, and Planctomycetes, vol. 4. Springer: New York, pp 568-573.

Camacho C, Coulouris G, Avagyan V, Ma N, Papadopoulos J, Bealer $\mathrm{K}$ et al. (2009). BLAST+: architecture and applications. BMC Bioinformatics 10: 421.

Cuív PÓ, Klaassens ES, Durkin AS, Harkins DM, Foster L, McCorrison J et al. (2011). Draft genome sequence of Turicibacter sanguinis PC909, isolated from human feces. J Bacteriol 193: 1288-1289.

Davis JJ, Xia F, Overbeek RA, Olsen GJ. (2013). Genomes of the class Erysipelotrichia clarify the firmicute origin of the class Mollicutes. Int J Syst Evol Microbiol 63: 2727-2741.

Desirò A, Salvioli A, Ngonkeu EL, Mondo SJ, Epis S, Faccio A et al. (2014). Detection of a novel intracellular microbiome hosted in arbuscular mycorrhizal fungi. ISME J 8: $257-270$.

Dutilh BE, Jurgelenaite R, Szklarczyk R, van Hijum SAFT, Harhangi HR, Schmid M et al. (2011). FACIL: fast and accurate genetic code inference and logo. Bioinformatics 27: 1929-1933.

Edgar RC. (2004). MUSCLE: multiple sequence alignment with high accuracy and high throughput. Nucleic Acids Res 32: 1792-1797.

Erbilgin O, McDonald KL, Kerfeld CA. (2014). Characterization of a planctomycetal organelle: a novel bacterial microcompartment for the aerobic degradation of plant saccharides. Appl Environ Microbiol 80: 2193-2205.

Gibson DG, Glass JI, Lartigue C, Noskov VN, Chuang R-Y, Algire MA et al. (2010). Creation of a bacterial cell controlled by a chemically synthesized genome. Science 329: 52-56.
Giovannoni SJ, Cameron Thrash J, Temperton B. (2014). Implications of streamlining theory for microbial ecology. ISME J 8: 1553-1565.

Glass JI, Assad-Garcia N, Alperovich N, Yooseph S, Lewis MR, Maruf $\mathrm{M}$ et al. (2006). Essential genes of a minimal bacterium. Proc Natl Acad Sci USA 103: 425-430.

Grant CW, McConnell HM. (1973). Fusion of phospholipid vesicles with viable Acholeplasma laidlawii. Proc Natl Acad Sci USA 70: 1238-1240.

Huseby DL, Roth JR. (2013). Evidence that a metabolic microcompartment contains and recycles private cofactor pools. J Bacteriol 195: 2864-2879.

Hyatt D, Chen GL, Locascio PF, Land ML, Larimer FW, Hauser LJ. (2010). Prodigal: prokaryotic gene recognition and translation initiation site identification. BMC Bioinformatics 11: 119.

Imelfort M, Parks D, Woodcroft BJ, Dennis P, Hugenholtz P, Tyson GW. (2014). GroopM: an automated tool for the recovery of population genomes from related metagenomes. PeerJ 2: e603.

Kerfeld CA, Heinhorst S, Cannon GC. (2010). Bacterial microcompartments. Annu Rev Microbiol 64: 391-408.

Kremer JR, Mastronarde DN, McIntosh JR. (1996). Computer visualization of three-dimensional image data using IMOD. J Struct Biol 116: 71-76.

Kube M, Siewert C, Migdoll AM, Duduk B, Holz S, Rabus R et al. (2013). Analysis of the complete genomes of Acholeplasma brassicae, A. palmae and A. laidlawii and their comparison to the obligate parasites from "Candidatus Phytoplasma”. J Mol Microbiol Biotechnol 24: 19-36.

Laslett D, Canback B. (2004). ARAGORN, a program to detect tRNA genes and tmRNA genes in nucleotide sequences. Nucleic Acids Res 32: 11-16.

Lazarev VN, Levitskii SA, Basovskii YI, Chukin MM, Akopian TA, Vereshchagin VV et al. (2011). Complete genome and proteome of Acholeplasma laidlawii. J Bacteriol 193: 4943-4953.

Lechner M, Findeiß S, Steiner L, Marz M, Stadler P, Prohaska S. (2011). Proteinortho: detection of (Co-) orthologs in large-scale analysis. BMC Bioinformatics 12: 124.

Li H, Handsaker B, Wysoker A, Fennell T, Ruan J, Homer N et al. (2009). The sequence alignment/map format and SAMtools. Bioinformatics 25: 2078-2079.

Li H. (2013). Aligning sequence reads, clone sequences and assembly contigs with BWA-MEM. arXiv [q-bioGN]. Available at http://arxiv.org/abs/1303.3997v2.

Li W, Godzik A. (2006). Cd-hit: a fast program for clustering and comparing large sets of protein or nucleotide sequences. Bioinformatics 22: 1658-1659.

Ludwig W, Schleifer K-H. (2005). Molecular phylogeny of bacteria based on comparative sequence analysis of conserved genes. In: Sapp J (ed). Microbial Phylogeny and Evolution: Concepts and Controversies. Oxford University Press: New York, USA, pp 70-98.

Ludwig W, Schleifer KH, Whitman WB. (2009). Revised road map to the phylum Firmicutes. In: De Vos P, Garrity GM, Jones D, Krieg NR, Ludwig W, Rainey FA et al. (eds). Bergey's Manual of Systematic Bacteriology, 2nd edn, vol. 3. Springer: New York, USA, pp 1-13.

Ludwig W, Strunk O, Westram R, Richter L, Meier H, Yadhukumar et al. (2004). ARB: a software environment for sequence data. Nucleic Acids Res 32: 1363-1371.

Malki S, Saimmaime I, De Luca G, Rousset M, Dermoun Z, Belaich JP. (1995). Characterization of an operon encoding an NADP-reducing hydrogenase in Desulfovibrio fructosovorans. J Bacteriol 177: 2628-2636. 
Mason OU, Case DH, Naehr TH, Lee RW, Thomas RB, Bailey JV et al. (2015). Comparison of archaeal and bacterial diversity in methane seep carbonate nodule and host sediments, Eel River Basin and Hydrate Ridge, USA. Microb Ecol 70: 766-784.

McCutcheon JP, Moran NA. (2012). Extreme genome reduction in symbiotic bacteria. Nat Rev Microbiol 10: 13-26.

Mogi T, Akimoto S, Endou S, Watanabe-Nakayama T, Mizuochi-Asai E, Miyoshi H. (2006). Probing the ubiquinol-binding site in cytochrome bd by sitedirected mutagenesis. Biochemistry 45: 7924-7930.

Moparthi VK, Hägerhäll C. (2011). The evolution of respiratory chain complex I from a smaller last common ancestor consisting of 11 protein subunits. J Mol Evol 72: 484-497.

Moriya Y, Itoh M, Okuda S, Yoshizawa AC, Kanehisa M. (2007). KAAS: an automatic genome annotation and pathway reconstruction server. Nucleic Acids Res 35: W182-W185.

Naito M, Morton JB, Pawlowska TE. (2015). Minimal genomes of mycoplasma-related endobacteria are plastic and contain host-derived genes for sustained life within Glomeromycota. Proc Natl Acad Sci USA 112: $7791-7796$

Nawrocki EP, Eddy SR. (2013). Infernal 1.1: 100-fold faster RNA homology searches. Bioinformatics 29: 2933-2935.

Ogawa Y, Ooka T, Shi F, Ogura Y, Nakayama K, Hayashi T et al. (2011). The genome of Erysipelothrix rhusiopathiae, the causative agent of swine erysipelas, reveals new insights into the evolution of firmicutes and the organism's intracellular adaptations. J Bacteriol 193: 2959-2971.

Orphan VJ, Hinrichs KU, Ussler W 3rd, Paull CK, Taylor LT, Sylva SP et al. (2001). Comparative analysis of methane-oxidizing archaea and sulfate-reducing bacteria in anoxic marine sediments. Appl Environ Microbiol 67: 1922-1934.

Parks DH, Imelfort M, Skennerton CT, Hugenholtz P, Tyson GW. (2014). CheckM: assessing the quality of microbial genomes recovered from isolates, single cells, and metagenomes. Genome Res 25: 1043-1055.

Pernthaler J, Glöckner F-O, Schönhuber W, Amann R. (2001). Fluorescence in situ hybridization (FISH) with rRNAtargeted oligonucleotide probes. In: Paul JH (ed). Marine Microbiology, vol. 30. Academic Press: Cambridge, MA, USA, pp 207-226.

Petersen TN, Brunak S, von Heijne G, Nielsen H. (2011). SignalP 4.0: discriminating signal peptides from transmembrane regions. Nat Methods 8: 785-786.

Pollack JD, Williams MV, McElhaney RN. (1997). The comparative metabolism of the mollicutes (Mycoplasmas): the utility for taxonomic classification and the relationship of putative gene annotation and phylogeny to enzymatic function in the smallest freeliving cells. Crit Rev Microbiol 23: 269-354.

Price MN, Dehal PS, Arkin AP. (2010). FastTree 2 - approximately maximum-likelihood trees for large alignments. PLoS One 5: e9490.

Razin S, Yogev D, Naot Y. (1998). Molecular biology and pathogenicity of mycoplasmas. Microbiol Mol Biol Rev 62: 1094-1156.
Razin S. (2006). The genus Mycoplasma and related genera (Class Mollicutes). In: The Prokaryotes. Springer: USA, pp 836-904.

Reyes-Prieto A, Barquera B, Juárez O. (2014). Origin and evolution of the sodium-pumping NADH: ubiquinone oxidoreductase. PLoS One 9: e96696.

Saunders SE, Burke JF. (1990). Rapid isolation of miniprep DNA for double strand sequencing. Nucleic Acids Res 18: 4948.

Seedorf H, Fricke WF, Veith B, Brüggemann H, Liesegang H, Strittmatter A et al. (2008). The genome of Clostridium kluyveri, a strict anaerobe with unique metabolic features. Proc Natl Acad Sci USA 105: 2128-2133.

Seemann T. (2014). Prokka: rapid prokaryotic genome annotation. Bioinformatics 30: 2068-2069.

Smith DG, Russell WC, Ingledew WJ, Thirkell D. (1993). Hydrolysis of urea by Ureaplasma urealyticum generates a transmembrane potential with resultant ATP synthesis. J Bacteriol 175: 3253-3258.

Stamatakis A. (2014). RAxML version 8: a tool for phylogenetic analysis and post-analysis of large phylogenies. Bioinformatics 30: 1312-1313.

Stojiljkovic I, Bäumler AJ, Heffron F. (1995). Ethanolamine utilization in Salmonella typhimurium: nucleotide sequence, protein expression, and mutational analysis of the cchA cchB eutE eut eutG eutH gene cluster. $J$ Bacteriol 177: 1357-1366.

Tivol WF, Briegel A, Jensen GJ. (2008). An improved cryogen for plunge freezing. Microsc Microanal 14: 375-379.

Torres-Cortés G, Ghignone S, Bonfante P, Schüßler A. (2015). Mosaic genome of endobacteria in arbuscular mycorrhizal fungi: Transkingdom gene transfer in an ancient mycoplasma-fungus association. Proc Natl Acad Sci USA 112: 7785-7790.

Wattam AR, Abraham D, Dalay O, Disz TL, Driscoll T, Gabbard JL et al. (2014). PATRIC, the bacterial bioinformatics database and analysis resource. Nucleic Acids Res 42: D581-D591.

Wu D, Jospin G, Eisen JA. (2013). Systematic identification of gene families for use as "markers" for phylogenetic and phylogeny-driven ecological studies of bacteria and archaea and their major subgroups. PLoS One 8: e77033.

Yang K, Zhang J, Vakkasoglu AS, Hielscher R, Osborne JP, Hemp J et al. (2007). Glutamate 107 in subunit I of the cytochrome bd quinol oxidase from Escherichia coli is protonated and near the heme d/heme b595 binuclear center. Biochemistry 46: 3270-3278.

Yutin N, Galperin MY. (2013). A genomic update on clostridial phylogeny: Gram-negative spore formers and other misplaced clostridia. Environ Microbiol 15: 2631-2641.

Zhang J, Hellwig P, Osborne JP, Gennis RB. (2004). Arginine 391 in subunit I of the cytochrome bd quinol oxidase from Escherichia coli stabilizes the reduced form of the hemes and is essential for quinol oxidase activity. J Biol Chem 279: 53980-53987.

Zheng SQ, Keszthelyi B, Branlund E, Lyle JM, Braunfeld MB, Sedat JW et al. (2007). UCSF tomography: an integrated software suite for real-time electron microscopic tomographic data collection, alignment, and reconstruction. J Struct Biol 157: 138-147.

Supplementary Information accompanies this paper on The ISME Journal website (http://www.nature.com/ismej) 